\title{
Millimeter Wave Antenna Design for 5G Applications
}

\author{
Issa Elfergani ${ }^{1}$, Abubakar Sadiq Hussaini ${ }^{1,2}$, Abdelgader Abdalla ${ }^{1}$, Jonathan Rodriguez ${ }^{1,3}$, \\ Raed Abd-Alhameed ${ }^{4}$ \\ ${ }^{1}$ Instituto de Telecomunicações, Aveiro, Portugal \\ ${ }^{2}$ School of Information Technology \& Computing, American University of Nigeria \\ ${ }^{3}$ University of South Wales, Pontypridd, CF37 1DL UK \\ ${ }^{4}$ Faculty of Engineering \& Informatics, University of Bradford, Bradford, BD7 1DP, UK
}

\begin{abstract}
In the current mobile networking regime, cellular service providers are continuously facing bandwidth constraints due the ever-growing demand for mobile services. As future emerging services become more rich in content, their QoS requirements become more stringent in terms of delivering high quality, low latency, and high bandwidth connectivity. This trend provided the impetus for 5th Generation (5G) cellular networks that are anticipated to be deployed in the coming years. A distinguishing feature for $5 \mathrm{G}$ is the use of millimetre wave technology as a means towards harnessing more available bandwidth. This places new design requirements on the antenna technology in terms of miniaturisation and multimode connectivity. This chapter describes a family of future antennas for $5 \mathrm{G}$ wireless mobile communication. These antennas constitute a rectangular patch element printed over $0.8 \mathrm{~mm} \mathrm{RF} 4$ substrate. The antennas have a simple structural layout and have low profile with over-all volume of $5 \times 5 \times 0.8 \mathrm{~mm}^{3}$. For bandwidth improvement purpose, a defected ground plane (DGP) approach was implemented, which demonstrated a broadband impedance response in the millimetre wave $(\mathrm{mmW})$ spectrum from $30 \mathrm{GHz}$ to $45 \mathrm{GHz}$, covering Ka band. Furthermore, an L-shaped slot was inserted over the right bottom corner of the patch in order to generate a notched-band feature at $40 \mathrm{GHz}$. To tune this rejected band, a lumped capacitor was attached on a appropriate location over the slot. The proposed antennas have good performance in terms of return loss, bandwidth coverage, antenna gain, and high efficiency over the entire frequency range.
\end{abstract}

\section{Introduction}

The mobile industry is continuously innovating new handset devices to be aligned with future emerging market trends. Today's handsets support video streaming, multimedia and fast surfing internet that is enabled by the Long Term Evolution (LTE) standard, what is commonly referred to as $4 \mathrm{G}$. The recent explosion in $4 \mathrm{G}$ communication technology has led to portable devices such as notebooks or laptop computers, operating on the LTE bands, namely LTE $700 \mathrm{MHz}$, LTE $2400 \mathrm{MHz}$, and LTE $2600 \mathrm{MHz}$; several LTE antenna designs have been reported recently [7-12], but are rigid in their design to cover new design frequencies to cover these lower frequency operational designs. 
The current communication regime is heading towards higher data rate connectivity as the market for rich multimedia content proliferates; this is supported by advances in nano-electronic devices and components that enable high processing power. In this context, the lower frequency bands that are being exploited by various communication networks are becoming congested forcing the industry stakeholders to investigate alternative pools of spectrum. . One such option is the UWB unlicensed bands that ranges from $3.1-10.6 \mathrm{GHz}$ that is being considered for indoor scenarios due to the shorter distances [13].

UWB antennas have gained huge consideration in the academia and industry for applications in wireless transmission systems. Thus, several antennas designs with numerous approaches were exploited to enhance the bandwidth coverage and enable the antenna to operate in the UWB frequency range [14-21]. Moreover, as there exists some standard narrow band standards within the UWB frequency region such as the wireless local area network (WLAN) for IEEE802.11a operating at $5.15-5.825 \mathrm{GHz}$ band, IEEE 802.16 WiMAX system operating at $3.3-3.7 \mathrm{GHz}, \mathrm{C}-$ band $(4.4 \mathrm{GHz}-5.0 \mathrm{GHz})$, and X-band operating at 7.725-8.275 GHz for ITU applications, this has led to performance degradation for UWB system due to co-channel interference. Thus, to avoid UWB devices from such interferences, an UWB antenna including filtering notch features is desired. The filtering notch performance may be accomplished by introducing a number of effective techniques as stated in [21-33].

However, although there are several advantages with the UWB standard, and in particular with UWB antennas such as wide bandwidth, low power consumption, and high data-rate wireless connectivity among devices within a personal operating space, the above mentioned antennas operating in such systems [1-33] are limited to a carrier frequency ranging between $700 \mathrm{MHz}$ and $2600 \mathrm{MHz}$ as in [1-12], and from $3 \mathrm{GHz}$ to $10 \mathrm{GHz}$ as in [14-33]. Still the antennas on offer are not flexible enough to provide tunning/coverage for frequencies outside this range.

The next mobile era is heading towards $5 \mathrm{G}$ communications. The race towards $5 \mathrm{G}$ is driven by the market place that is forecasting mobile traffic to increase exponentially over the next decade. This is not only constitutes traditional mobile services such as high-speed data, but also future emerging use-cases such massive machine-type communication and the tactile internet. In synergy, these will place new design requirements on the mobile system that includes offering high capacity services, super low latency connectivity and high reliability. Clearly, current 4G systems that were designed preliminary for supporting medium-to-high data rate service are not engineered to support the expected diverse traffic types, nor able to have inherent capacity to support the growth in data; the existing cellular networks may need to deliver as much as a thousand times the capacity relative to current levels, and it is clear that legacy mobile systems will reach a saturation point.

To provide the $5^{\text {th }}$ Generation mobile network the necessary tool to deliver next generation services, will require at first more spectrum since current capacity enhancement techniques can only deliver stepwise gains. In order to solve this problem, the 5G standardization community is looking towards the use of the higher frequency spectrum, the so called millimeter wave bands $(20-300 \mathrm{GHz})$, where a huge amount of untapped spectrum pools are available.

In fact, the millimeter wave bands have been recommended to be significant and essential part of the 5G mobile network in order to provide multi-gigabit communication services such as high definition television (HDTV) and ultrahigh definition video (UHDV) [34]. It is believed that from both the regulatory and technological perspectives, the initial spectrum allocation for $5 \mathrm{G}$ will be between the bands of $24 \mathrm{GHz}$ up to $57 \mathrm{GHz}$. It has been suggested/ recommended that the mobile industry prioritize bands within the $25.25-29.5 \mathrm{GHz}$ and the $36-40.5 \mathrm{GHz}$ frequency blocks as primary targets for 5G (World Radio communication Conference 2019 -WRC-19) [35]. In this 
context, the efficient deployment of 5G systems will require the design of even more compact yet efficient antennas. This provides the impetus for a new breed of handset design that in principle should be multimode in nature, energy efficient, and above all able to operate at the mm wave band, placing new design drivers on the antenna design.

There has been unprecedented activity within the antenna research community to come up with efficient antenna designs for use in 5G paradigm, in particular designs that operate in dual 5Gfrequency bands, i.e., $28 \mathrm{GHz}$ and $38 \mathrm{GHz}$ bands. The mm-wave $5 \mathrm{G}$ antenna designs must take into consideration the high propagation loss due to atmospheric absorption at millimetre waves [36]. Furthermore, the $5 \mathrm{G}$ antennas are expected to have a high gain, efficiencies and bandwidth greater than $1 \mathrm{GHz}$. Several investigations carried out on wireless communication that employ a printed antenna technology for mm-wave bands [37-40]. Microstrip antennas are exploited for various applications owing to their simple and low profile features. However, microstrip antenna suffers from narrow bandwidth typically $2-5 \%$, very low radiation efficiency $(<10 \%)$ and low gain $(<0 \mathrm{dBi})$ [41]. All these drawbacks may lead to reduction in the antenna gain and efficiency considerably at mm-wave frequencies. The printed monopole antenna has also been broadly used for mobile applications due to inherent attributes such as low profile, planar structure, multiband properties, low cost, moderate to high gain, and ease of fabrication. Various antenna designs [4247] have been proposed for $5 \mathrm{G}$ applications, which operate in this new millimeter-wave spectrum. Although these antenna designs cover the desired $5 \mathrm{G}$ allocated frequency bands, there are very few of them, which provides a wide frequency bandwidth. Moreover, the antennas that operate over a broad frequency range, but also have limited agile flexibility in their design to overcome interference $[42,44]$.

To mitigate interference and to have a more flexible inherent design, we re-engineer the printed monopole design, and propose a wide band monopole printed antenna encompassing simple and effective approaches towards enhancing the bandwidth, power gain, efficiency and reducing the interferences at mmwave frequencies. This chapter first considers the design procedure based on a single band monopole antenna, that evolves through stepwise enhancements towards our final goal, an antenna that can operate with wideband characteristics. The enhancements consider notch features that were introduced by embedding an L-shaped slot on the right bottom corner of the radiating patch. To control the created rejected band, a lumped capacitor was positioned on the best location within the L-shaped slot and by changing its capacitance values; the notched-band can easily be shifted downwards over a wide and continues frequency range. The proposed antenna is demonstrated to be a suitable candidate antenna to operate over the 36 to $40.5 \mathrm{GHz}$ frequency block, aligned with the frequencies range under consideration by the WRC-19 [35].

\section{Antenna Design and Procedure}

The mmwave printed monopole antenna structure and synthesis is shown in Figure 1. The proposed antenna is constructed on a SLXSW, FR4 substrate with $0.8 \mathrm{~mm}$ thickness, dielectric constant $\varepsilon r=4.4$ and loss tangent $\tan \delta=0.017$. The dimensions of the radiating patch (PL x PW) is $2.5 \mathrm{~mm} \times 2.5 \mathrm{~mm}^{2}$. The antenna is fed via a $50-\mathrm{Ohm}$ microstrip transmission line having a width and length of FL x FW. The other side of the substrate has a finite rectangular copper ground plane with dimensions GL x GW as depicted in Figure 1,b. 


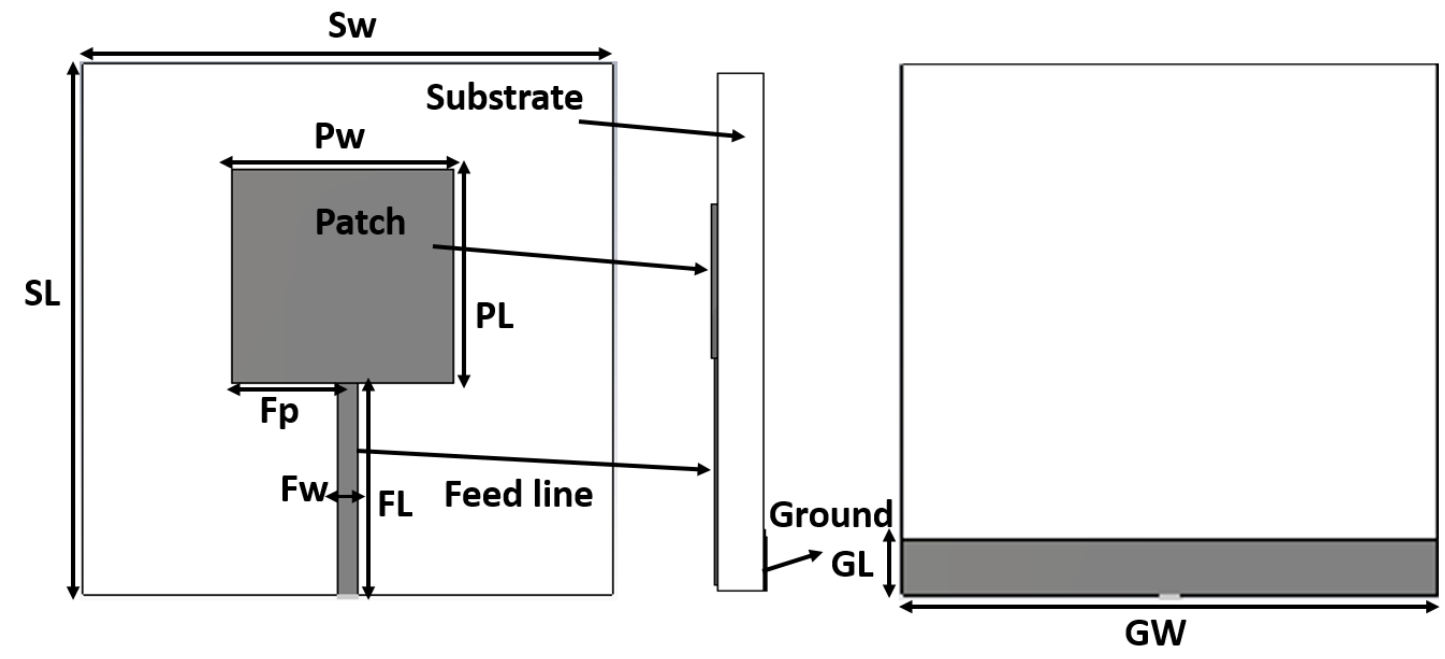

a
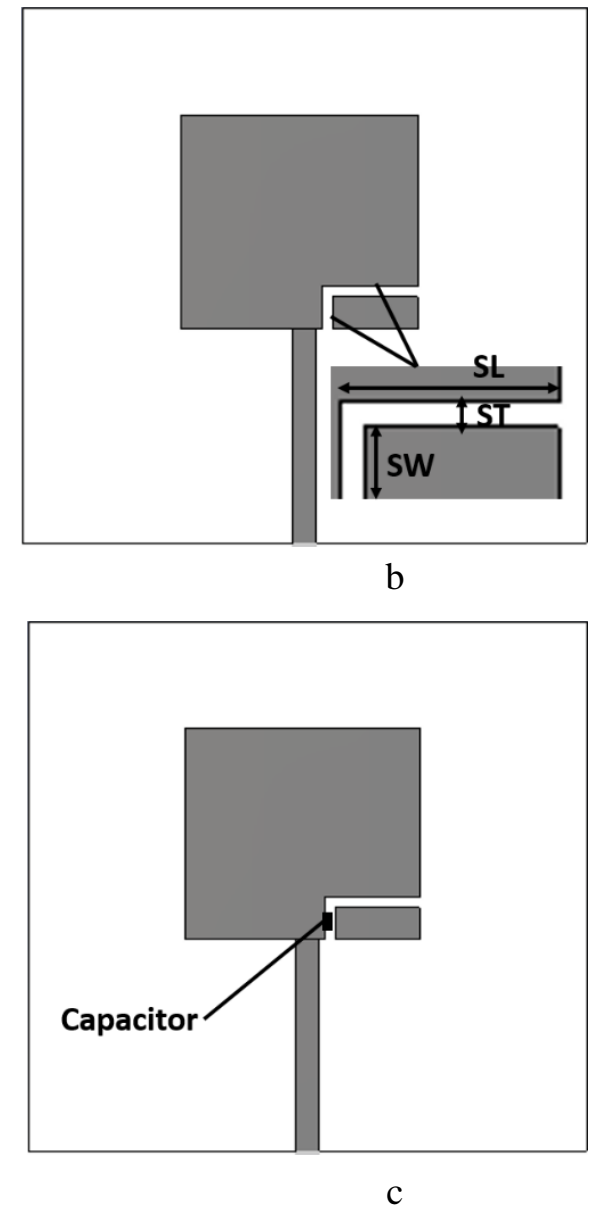

Figure 1. The main antenna structure, (a) antenna with DGP ,(b) antenna with L-slot, (c) antenna with attached capacitor

This optimised ground plane shape and dimensions has helped in improving the impedance matching of the proposed antenna. The optimized parameters are summarized in Table 1. An embedded L-Shaped slot dimension of SL x SW x ST was introduced on the right bottom corner over the patch and close to the feeding strip as shown in Figure1.b, this slot was added in an appropriate location in order to produce a rejected band at around $40 \mathrm{GHz}$. 
Table1. The full dimensions of the proposed antenna

\begin{tabular}{|c|l|}
\hline Parameters & Volume $(\mathrm{mm})$ \\
\hline $\mathrm{Pw}$ & 2.5 \\
\hline $\mathrm{PL}$ & 2.5 \\
\hline Fp & 1.25 \\
\hline FL & 2 \\
\hline Fw & 0.15 \\
\hline Sw & 5 \\
\hline SL & 5 \\
\hline GL & 0.5 \\
\hline GW & 5 \\
\hline SL & 1 \\
\hline ST & 0.15 \\
\hline SW & 0.75 \\
\hline &
\end{tabular}

\section{Antenna Optimisation and Analysis}

To further investigate the influences of the key antenna parameters on its performance, extensive parametric studies were carried out. The optimized values for the proposed design are tabulated in Table 1.Three parameters were chosen for this analysis, that include the ground plane length, feed position and type of used substrate; these three parameters were deemed as the most sensitive ones in defining the desired frequency bands along with best impedance matching. Each simulation was run with only one parameter varied, while the other parameters remain unchanged. The optimization analysis of the proposed antenna parameters were done with the aid of using the CST EM simulator [48].

\subsection{The influence of ground plane length (GL).}

The influence of the length of the ground plane was analysed by examining the variations in the S11 against the ground plane length. The length of the ground plane was varied from $3.5 \mathrm{~mm}$ to $0.5 \mathrm{~mm}$, when the ground plane length set at $3.5 \mathrm{~mm}$, the proposed antenna exhibits a narrow bandwidth at around $38 \mathrm{GHz}$. 


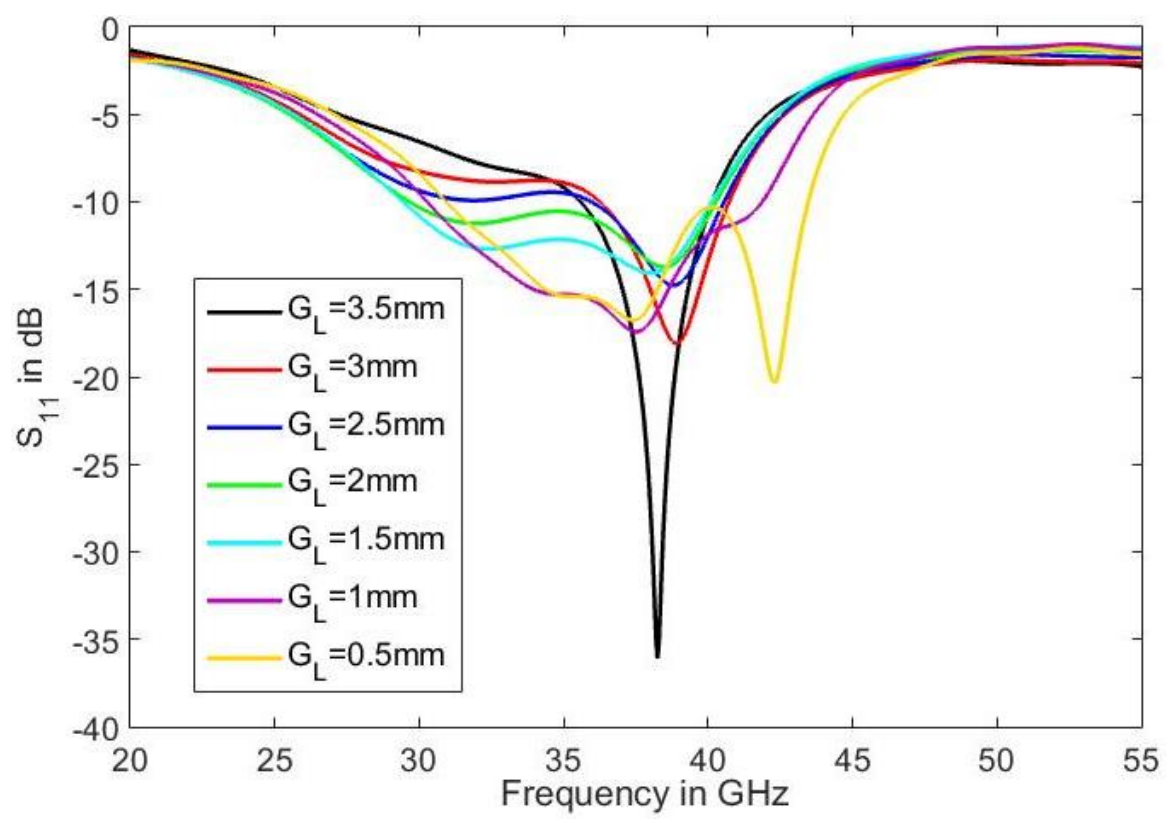

Figure 2. Simulated return loss $\left(\mathrm{S}_{11}\right)$ for different ground plane lengths of the first version of the proposed antenna

On the other hand, this antenna demonstrates a wide frequency range from $30 \mathrm{GHz}$ up to around $40 \mathrm{GHz}$, when the GL was varied from $2.5 \mathrm{~mm}$ up to $1.5 \mathrm{~mm}$. When the ground plane length decreased to $1 \mathrm{~mm}$, the higher resonant frequency was increased to $42 \mathrm{GHz}$, this makes the antenna operates over a broad bandwidth from $30 \mathrm{GHz}$ to $42 \mathrm{GHz}$. However, when the GL sets at $0.5 \mathrm{~mm}$, the bandwidth of the proposed antenna was further improved to cover the operational range from $30 \mathrm{GHz}$ to $45 \mathrm{GHz}$ as indicated in Figure 2, in which case this GL value was selected to be as the optimum value for the length of the ground plane for the proposed antenna design.

\subsection{The effect of feeding strip position (Fp).}

The effects of the feed line position are illustrated in Figure 3. In this analysis, the position of the feed line is primarily set to the edge of the design structure, which corresponds to $1 \mathrm{~mm}$, which is then shifted in steps of $0.25 \mathrm{~mm}$ closer to the end of the other edge, which is at $2 \mathrm{~mm}$. One can clearly see, that when the feeding strip is set at $0.5 \mathrm{~mm}$ and $1.5 \mathrm{~mm}$, the proposed structure shows a good impedance matching of $23 \mathrm{~dB}$ return loss at $25 \mathrm{GHz}$. When the position of the feeding strip is moved over the values of $0.75 \mathrm{~mm}, 1 \mathrm{~mm}, 1.75 \mathrm{~mm}$ and $2 \mathrm{~mm}$, the antenna resonant frequency is shifted upwards to around $30 \mathrm{GHz}$. Although, the proposed antenna with the above-mentioned feeding position values show a good impedance matching at around $25 \mathrm{GHz}$ and $30 \mathrm{GHz}$, this is still considered as a narrow bandwidth resonator which does not meet the targeted design value. But, when the position of the feeding line is set at $1.25 \mathrm{~mm}$, the bandwidth of the proposed antenna was significantly improved to cover a wide frequency range from $30 \mathrm{GHz}$ to $45 \mathrm{GHz}$ as depicted in Figure 3. Therefore, this value of $1.25 \mathrm{~mm}$ was picked to be as the best value of the feeding location. 


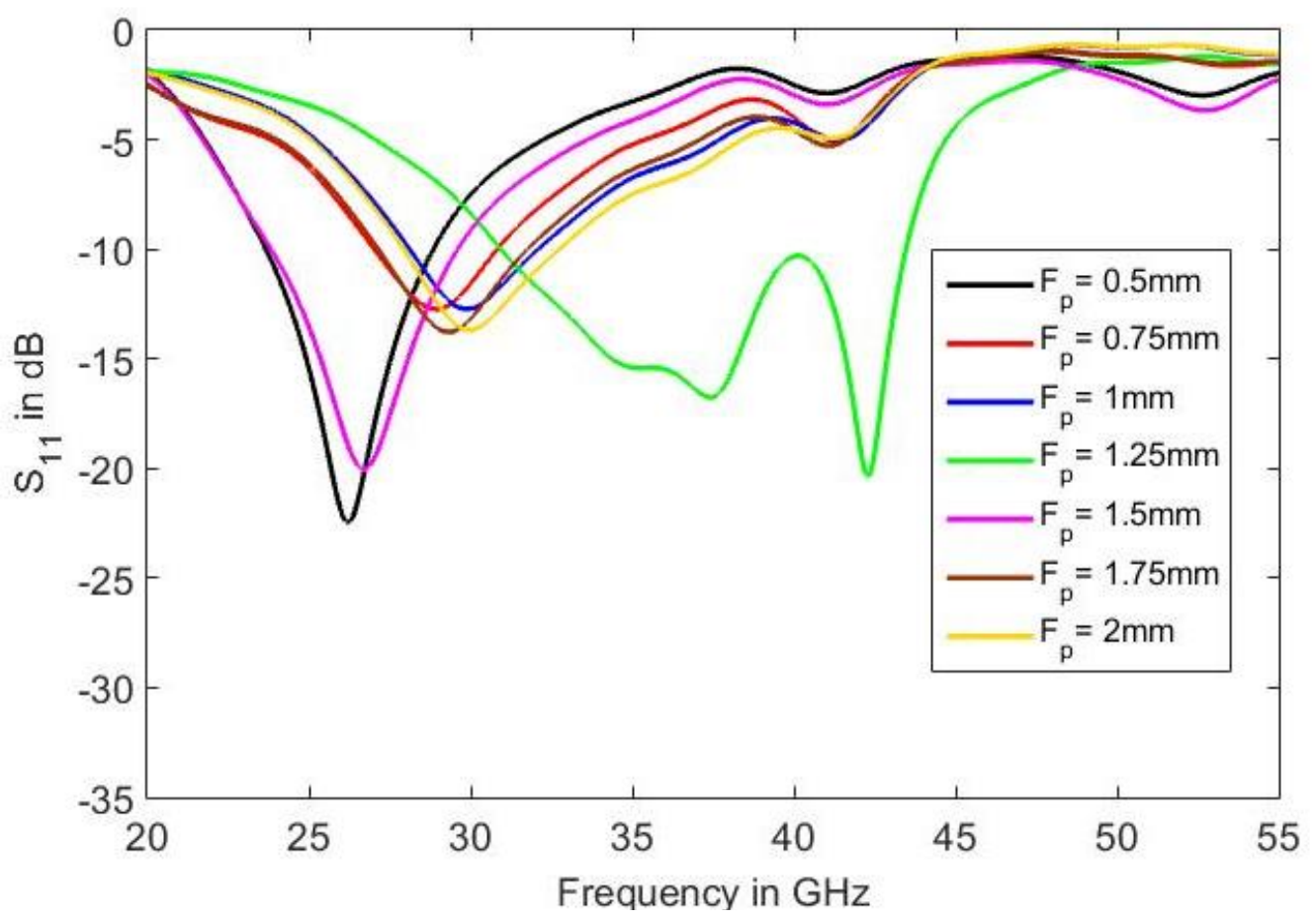

Figure 3. Simulated return loss $\left(\mathrm{S}_{11}\right)$ for different feeding line position on the first version of the proposed antenna

\subsection{The influences of the substrate type}

To estimate the effectiveness of permittivity of the applied substrate, the variation of the permittivity of the substrates against the $S 11$ response is investigated as depicted in Figure 4. This examination was implemented in order to accomplish the best behaviour for the proposed antenna at the targeted wide bandwidth range. Four substrates with different levels of permittivity were used in this study, where the wide band frequency response was analysed, as indicated in Figure 4. These include (FR4 $\varepsilon r=4.4),($ RT/duriod $5880 \varepsilon r=2.33),($ RT/duriod $5870 \varepsilon r=2.33)$ and (Roger RT $6006 \varepsilon r=6.15)$.

It is appeared that when the proposed radiator is printed over the RT/duriod $5870 \mathrm{\varepsilon r}=2.33$ and Roger RT $6006 \varepsilon r=6.15$, it exhibits a resonant frequency only at 50GHz, which does not meet the broad bandwidth target defined within this work. On other hand, when both the FR4 $\varepsilon r=4.4$ and Roger RT $6006 \varepsilon r=6.15$ were utilised, the antennas achieves a very wide frequency range from $30 \mathrm{GHz}$ up to around $45 \mathrm{GHz}$, as depicted in Figure 4, that is more suited to $5 \mathrm{G}$ applications. However, as the permittivity of RT $6006 \varepsilon r=6.15$ is a quite high, this will affect and impair the performance of the antenna, particularly in terms of the antenna gain and efficiency. Thus, the FR4 $\varepsilon r=4.4$ was selected to be used as the substrate materiel within this investigation. 


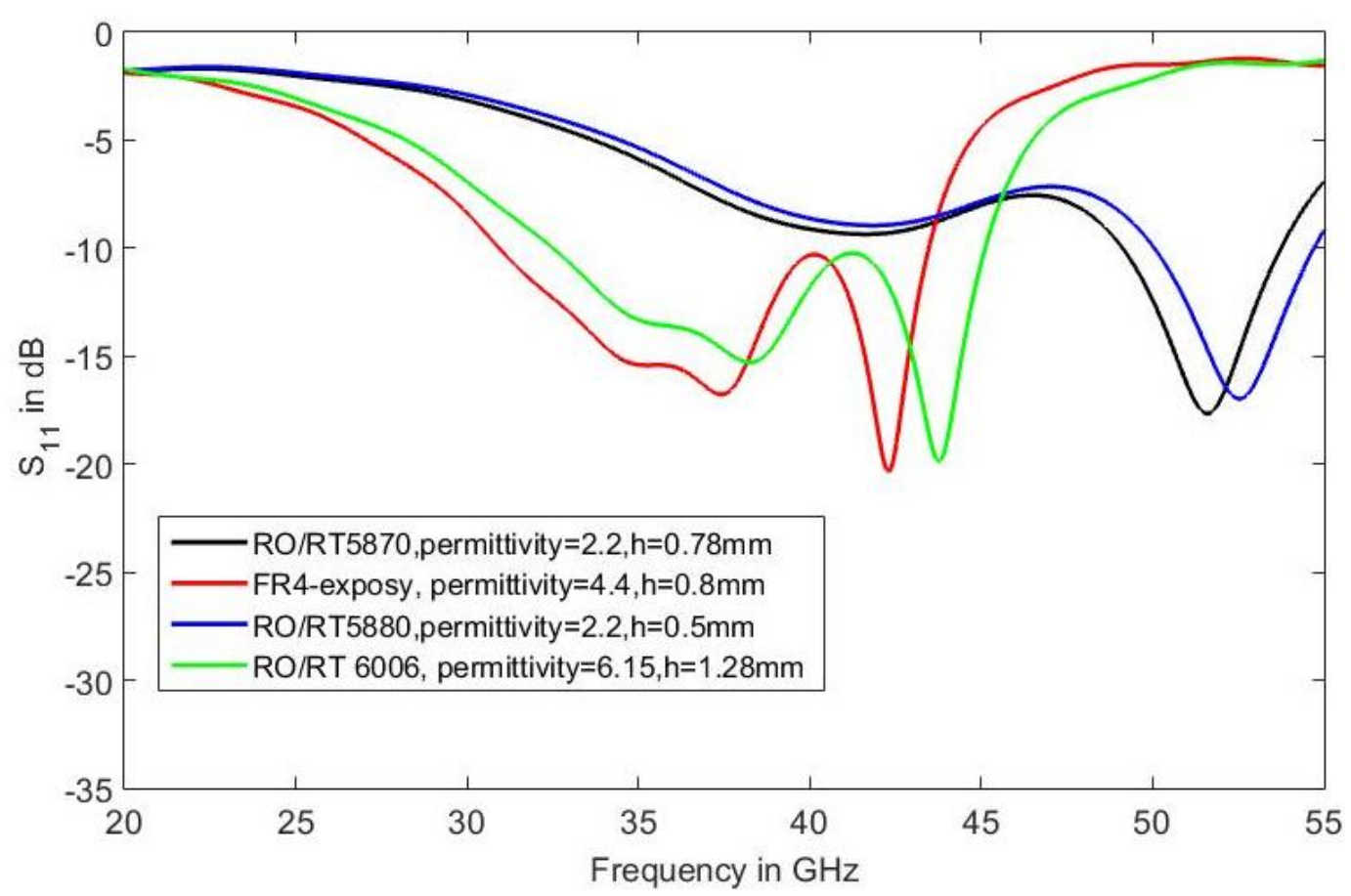

Figure 4. Simulated return loss $\left(\mathrm{S}_{11}\right)$ for different substrate materials on the first version of the proposed antenna

\section{MMwave Antenna Design with notched frequency band}

As was previously explained, to come up with the optimum wide band frequency mmwave antenna, several procedures were implemented. The first antenna design was implemented with a full ground plane, that resulted in good impedance matching at $37.5 \mathrm{GHz}$ as depicted in Figure 5. However, as the main target of this work was to design and develop a compact antenna that is able to operate over a wider frequency range within the mmwave spectrum, there was a need to look at alternative techniques such as the defected ground plane (DGP) approach.

In general, the conventional microstrip antenna structure also suffer from constraints and limitations such as single operating frequency, low impedance bandwidth, low power gain and size increasing. Thus, several approaches have been taken into consideration in order to meet the above-mentioned limitations. These approaches include, using stacking, different feeding methods, high permittivity dielectric substrate, Frequency Selective Surfaces (FSS), Electromagnetic Band Gap (EBG), Photonic Band Gap (PBG), Metamaterial, and so forth. However, none of these techniques can meet the aforementioned constraints. For example using different feeding approach can improve the antenna bandwidth, but it might be considered complex and even high cost, the use of substrate with high permittivity will help in enhancing the antenna bandwidth, but will severely affect the antenna gain and efficiency, EBG and PBG are deemed as attractive avenues to improve the antenna performance, but both are considered not so simple and low cost approaches.

The Defected Ground Plane (DGP) has been given more attention among all the above-mentioned approaches mainly because of its simple structural design. In fact, embedded single or multiple slots or defects over the ground plane of the microstrip circuits are referred to as Defected Ground 
Plane/Structure. The DGP is deemed as a promising procedure to effectively improve the performance of the patch antenna. Such DGP approach is integrated within the antenna design in which lead to several advantages including, improved radiation properties, antenna size reduction, suppression of harmonics, reduced cross polarization and improved isolation in MIMO antenna. The DGP also is an avenue that contributes in mitigating surface wave. This can be done by partially etching the ground structure of an antenna. Furthermore, DGP may enable the antenna engineers to adjust ground field shape, and since microstrip antennas suffer from severe surface wave losses, so, in turn the DGP would improve the antenna performance.

In other word, the ground plane of the antenna is defected in order to upgrade the antenna performance. These defects can be a shape of periodic or non-periodic. Fundamentally, DGP is a resonant gap that is able to disturb the current distribution in the ground plane of the antenna. This alteration of the current distribution creates an impact on the characteristics of the antenna by disturbing the shunt capacitance and series inductance. As has been understood from [49] that, a DGP creates a parallel-tuned circuits, where capacitance, inductance and resistance change according to the structure of the DGP. This is the key factor that the DGP is tuned to different frequencies and provides multiband operation and enhanced bandwidth.

All these advantages have made the DGP a promising, easy and simple avenue to mainly improve the antenna bandwidth. Thus, within this chapter the DGP was implemented to enhance the antenna bandwidth. As can be from Figure 5 that when the ground plane of the antenna was cut to form the DGP, the bandwidth was enhanced to cover a wide range from $30 \mathrm{GHz}$ to $45 \mathrm{GHz}$ compared to the antenna with full ground plane that has only a narrow band around $37.5 \mathrm{GHz}$.

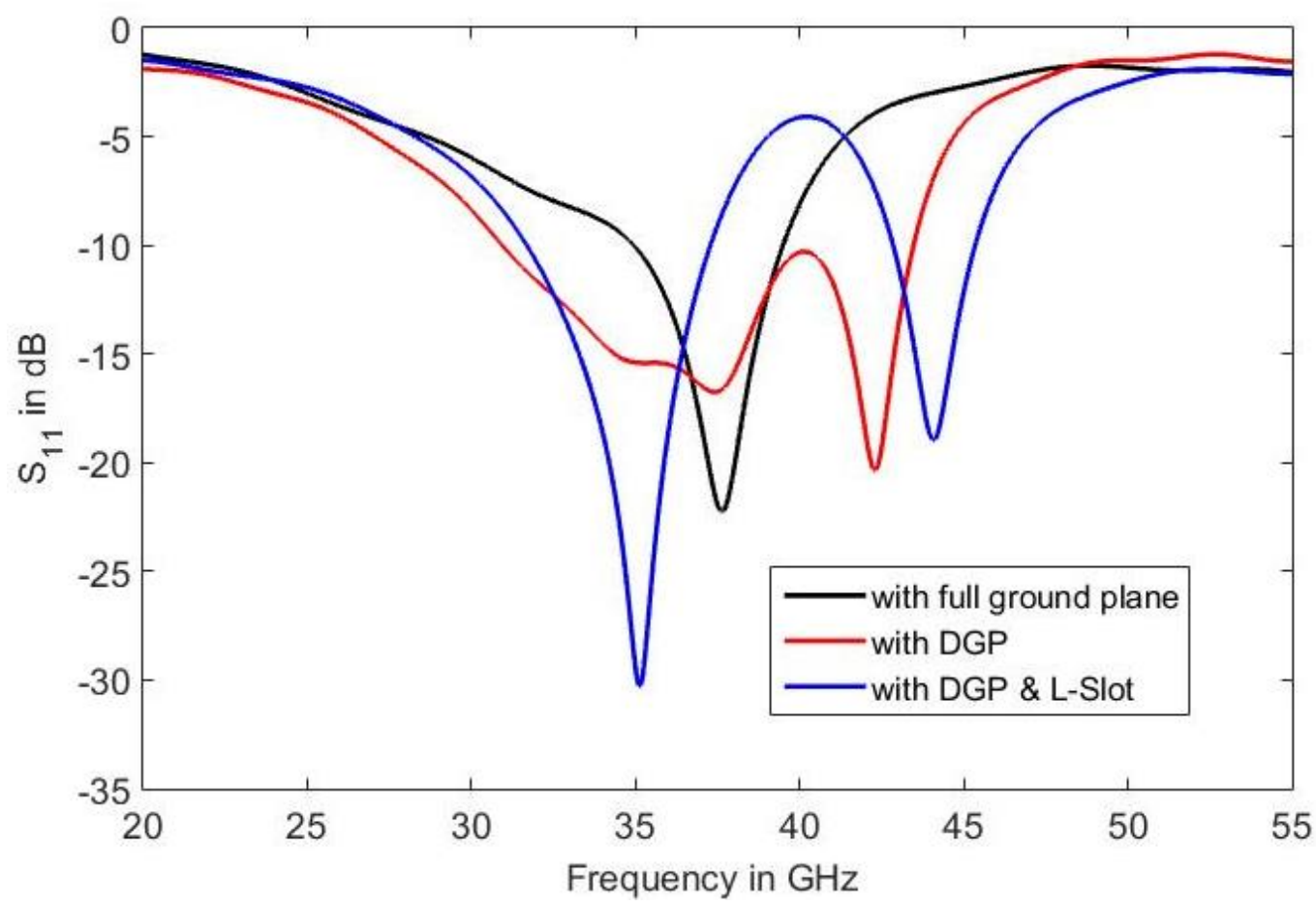

Figure 5. The S11 variations of the antenna with full ground plane, with DGP and with DGP\& L-slot

However, the antenna with DGP operates over a broad frequency range of mmwave spectrum i.e. $30 \mathrm{GHz}$ to $45 \mathrm{GHz}$, which is subject to expected severe interferences among the co-channels. To 
mitigate or/and avoid such interferences, a filter is needed to offer rejection to unwanted frequencies in the range of the targeted operating band in order to not only to avoid an envisaged interference from other communication applications but also to improve its own systems performance. However, to use an external band-rejection filter along with the antenna will lead to design complexity, large size and high cost.

The antenna designers have addressed this by using other simple and less complex avenues to replace the external filters, these approaches include, embedding parasitic elements, EBG, and inserting different slits shapes over the radiating element or ground plane of the antenna systems. This will not only create a notched band feature, but will also keep the antenna footprint unaltered. Therefore, within this design, an L-shaped slot was introduced over a proper location on the patch as shown in Figure 1.b. The antenna together with the DGP and L-slot still show a smooth wide frequency range from $30 \mathrm{GHz}$ to $45 \mathrm{GHz}$, but a notched band around $40 \mathrm{GHz}$ was generated as indicated in Figure 5.

The antenna power gains and efficiencies of the antenna with DGP and the antenna including DGP and L-slot are shown in Figure 6. It is obvious that the antenna without the rejected band (antenna with DGP) exhibits smooth power gain values ranging from around $3.95 \mathrm{dBi}$ up to $5.8 \mathrm{dBi}$ over the entire frequency range. However, the antenna with the DGP and the L-Slot show a stable power gain value from $3.99 \mathrm{dBi}$ to around $6 \mathrm{dBi}$, except at the $40 \mathrm{GHz}$ the gain decreases sharply to $-5.6 \mathrm{dBi}$ where the filtering notch was produced.

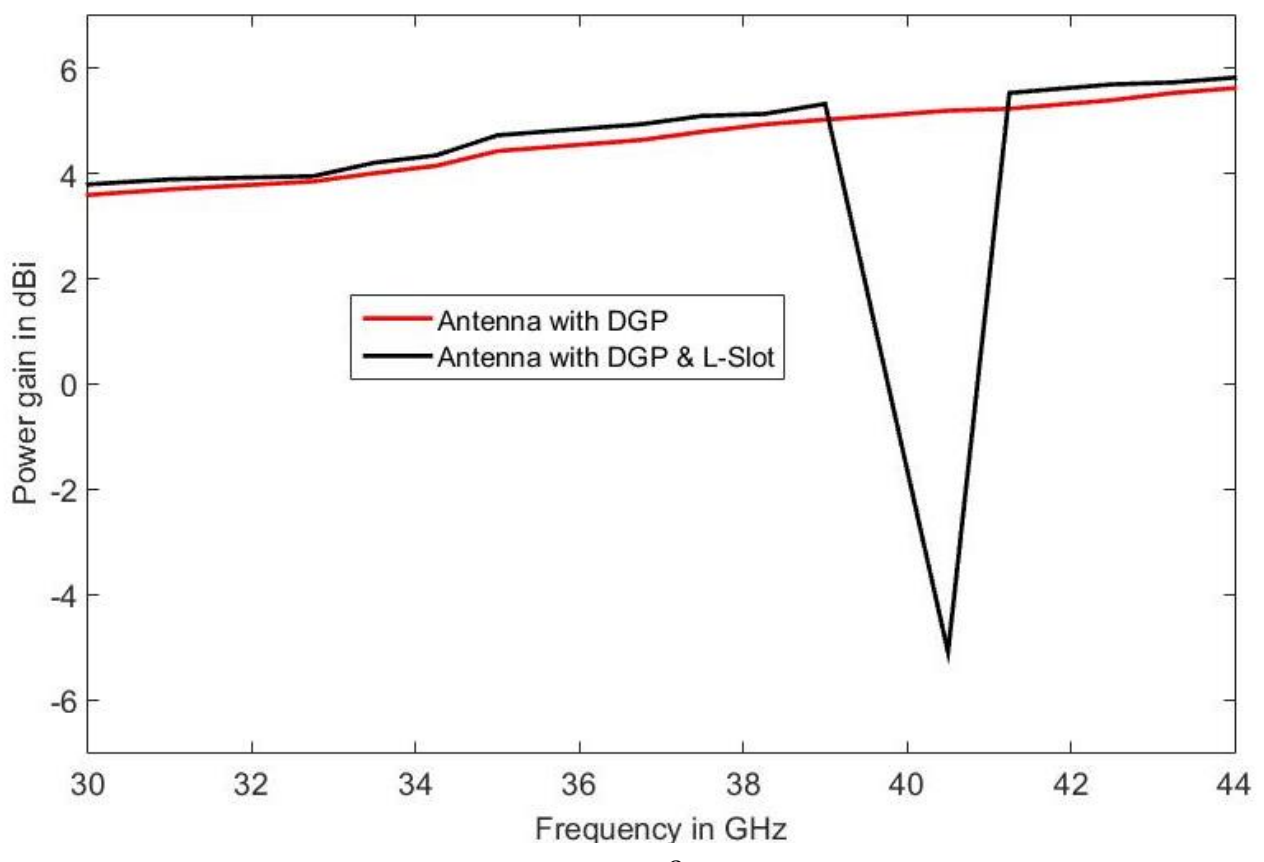




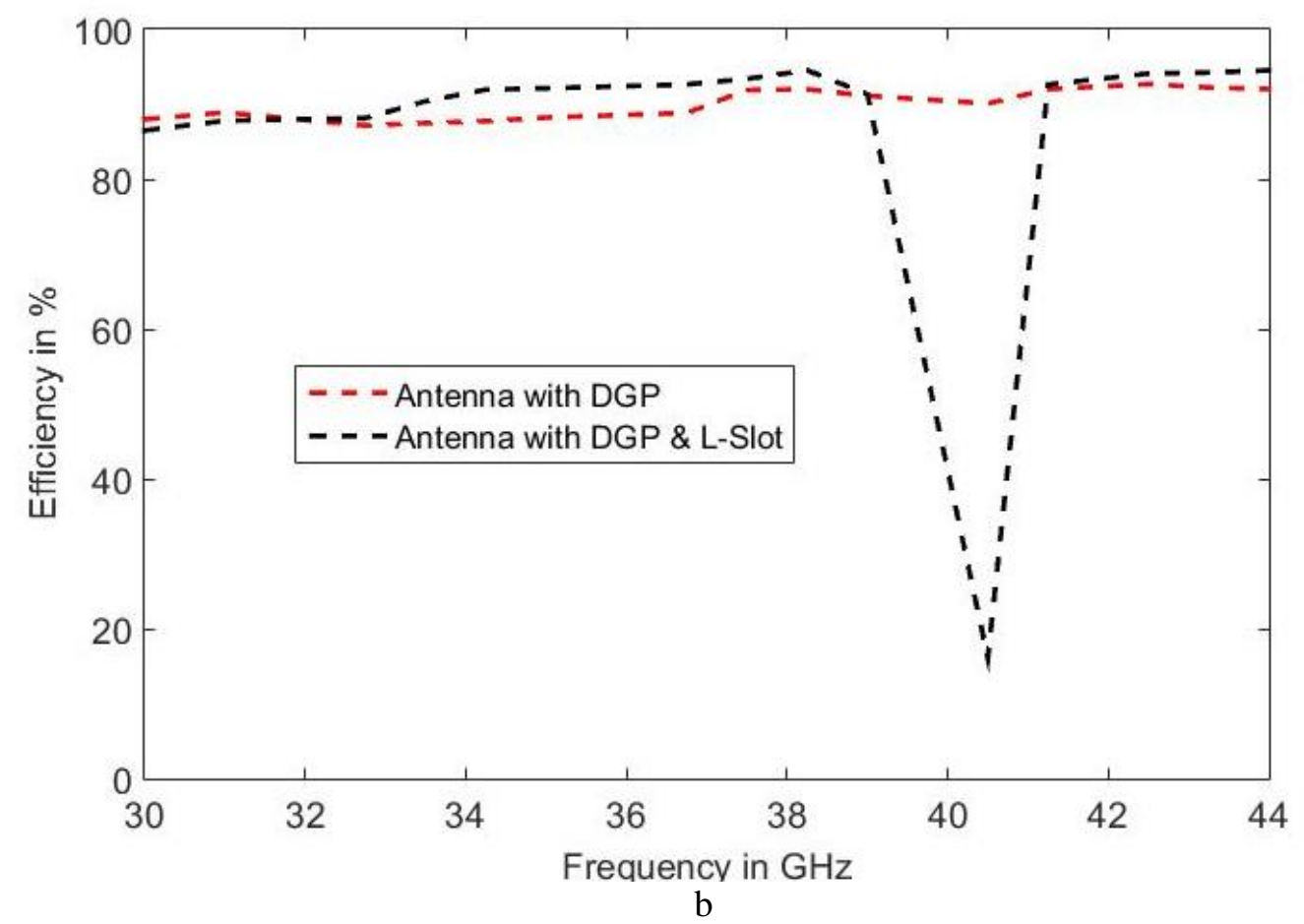

Figure 6. The power gains (a) and effiecnies (b) of the proposed antennas with only DGP and with DGP\&L-slot

The radiation efficiencies of the antenna version with DGP varies from $86 \%$ to around $90 \%$ over the whole desired wide bandwidth, while the antenna version with the DGP and combined L-Slot shows radiation efficiencies varying from $83 \%$ to $84 \%$ at the lower frequencies (30GHz up to $33 \mathrm{GHz}$ ), whilst showing a smooth curve at around $92 \%$ at the higher frequency bands, except at $40 \mathrm{GHz}$, where the efficiency largely drops to a value of around 18\%; as expected the efficiencies are in agreement with the obtained gain.

\section{MMwave Antenna Design with Loaded Capacitor}

Although the version of the antenna (with DGP and L-slot) maintains the same wide frequency range from $30 \mathrm{GHz}$ to $45 \mathrm{GHz}$ with an inherent filtering notch at the $40 \mathrm{GHz}$ frequency for interference rejection, the design is rigid in nature; once the antenna is fabricated, it is not feasible to alter/shift the produced rejected band. The generated filtering band should be to tuned/switched to cover multiple bands.

The tuneable notched-bands have come up with several advantages over their conventional counterparts of fixed notched-bands. The antenna with the tuned rejected band frequencies can be exploited to easily avoid interference over multiple frequency bands. This will significantly contribute in size reduction and towards minimising the cost of the hardware. Their desirable attributes are spurring the proliferation of their application, and likely to play a key role in 5G systems. 
In recent years, novel communication architectures are being developed (software defined radio, MIMO and cognitive radio) as part of the evolution towards 5G, which will alleviate the stress on legacy wireless networks and open new and effective prospects for drastic improvements in network bandwidth and efficiency. Therefore, in order to implement such architectures, antennas that are able to operate in wideband operation are required. However, the defined frequency band for wide band systems may cause interference to the existing narrow wireless communication systems. Therefore, wide band antennas with fixed rejected band can be tuned to operate over a larger range of frequencies while reconfiguring the notched band over a desired range, in which effectively enhancing the antenna performance. In addition, it can divide the whole wide band into a few sub-bands. This will create more flexibility for practical applications. Thus, within this chapter the created notched band of $40 \mathrm{GHz}$ was tuned by positioning a lumped capacitor over an appropriate location on the L-Slot as shown in Figure 1.c. The generated notched-band can be widely and continuously tuned to cover the range of $39,37 \mathrm{GHz}, 35 \mathrm{GHz} \mathrm{GHz}$ and $33 \mathrm{GHz}$, by varying the capacitance of the attached capacitor over the values of $0.5 \mathrm{pf}, 1.5 \mathrm{pf}, 5 \mathrm{pf}$ and $7 \mathrm{pf}$ respectively as shown in Figure 7.

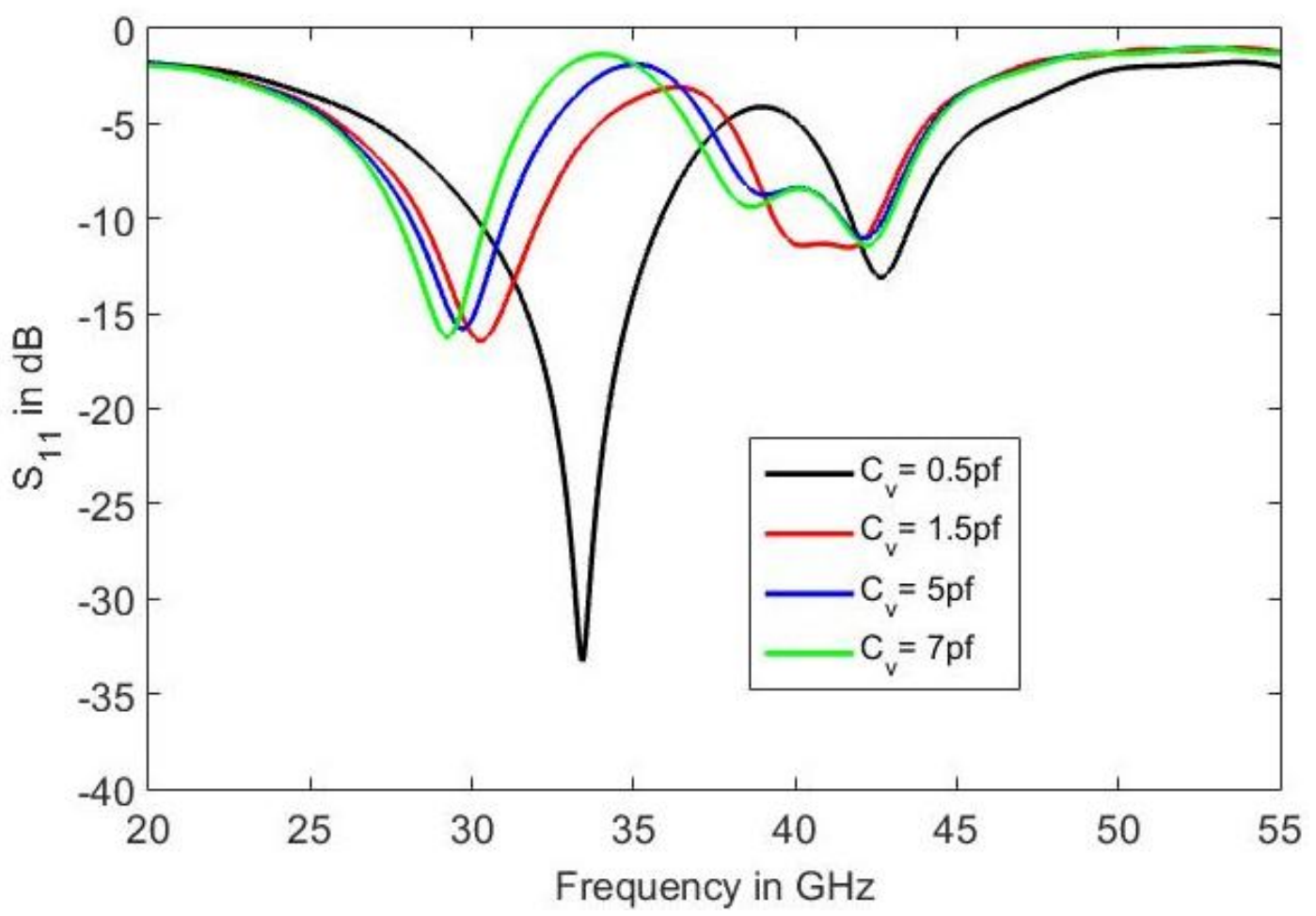

Figure 7. The S11 variations of the antenna with attached capacitor

The power gains and efficiencies of the antenna with tuneable notches are indicated in Figure 8. In the scenario of the antenna version with tuneable rejected bands, the power gain ranges from $3.9 \mathrm{dBi}$ to around $6.2 \mathrm{dBi}$ over the all frequency continuous range, except at four targeted notched bands, namely $39 \mathrm{GHz}, 37 \mathrm{GHz}, 35 \mathrm{GHz}$ and $33 \mathrm{GHz}$ (capacitance values from $0.5,1.5,5$ and $7 \mathrm{pf}$ ), where the gain values of the four rejected bands were considerably dropped to $-2.5 \mathrm{dBi},-2.8 \mathrm{dBi}$, $-2.6 \mathrm{dBi}$ and $-2.7 \mathrm{dBi}$ respectively. Also, radiations efficiencies from $83 \%$ to $92 \%$ were achieved when the capacitance was varied from $0.5 \mathrm{pf}$ up to $7 \mathrm{pf}$, expect at the notched bands of $39 \mathrm{GHz}$, 
$37 \mathrm{GHz}, 35 \mathrm{GHz}$ and $33 \mathrm{GHz}$, where the efficiencies of the proposed design were reduced to $19 \%$ $, 18 \%, 20 \%$ and $20 \%$, respectively.

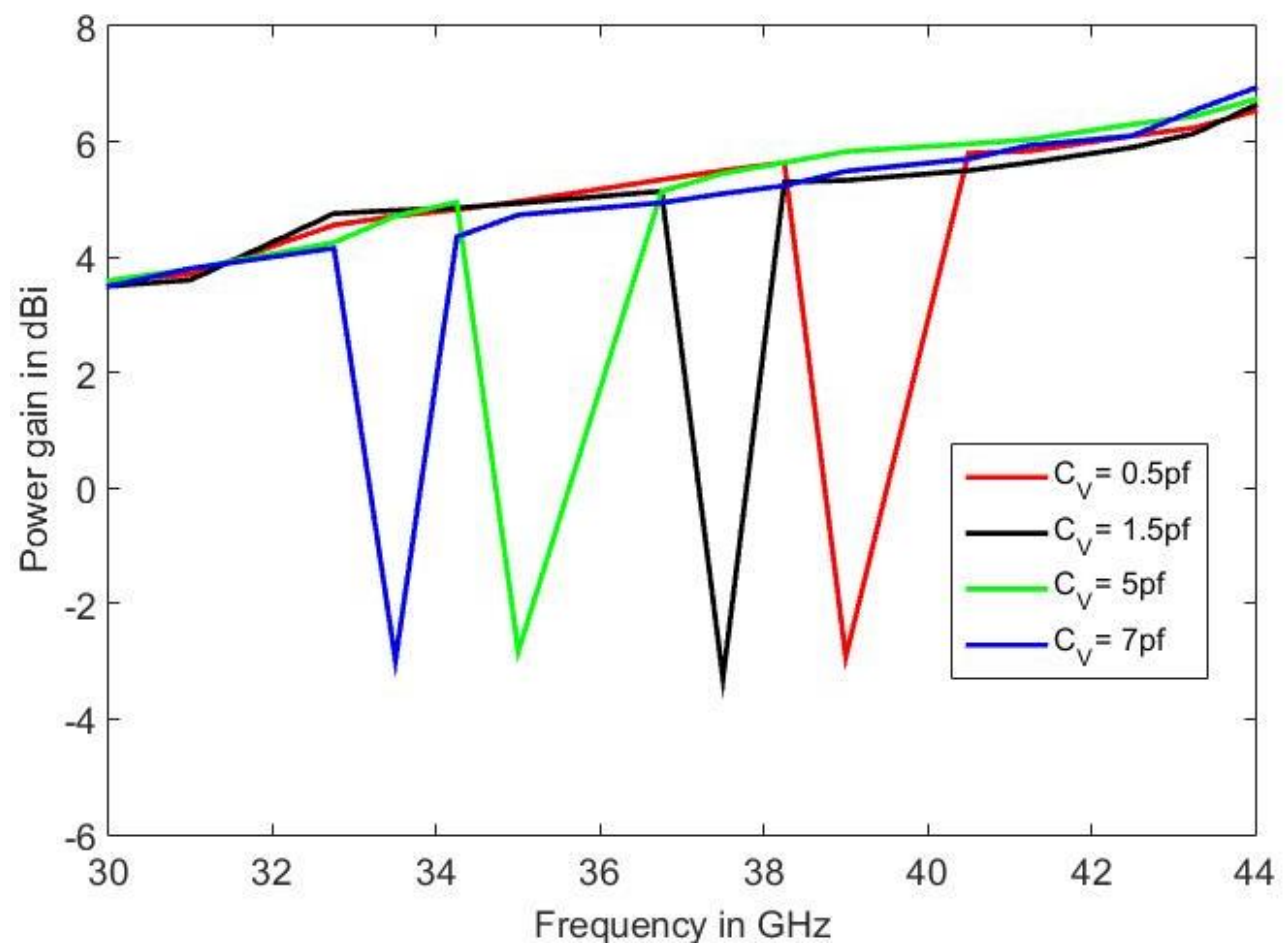

a

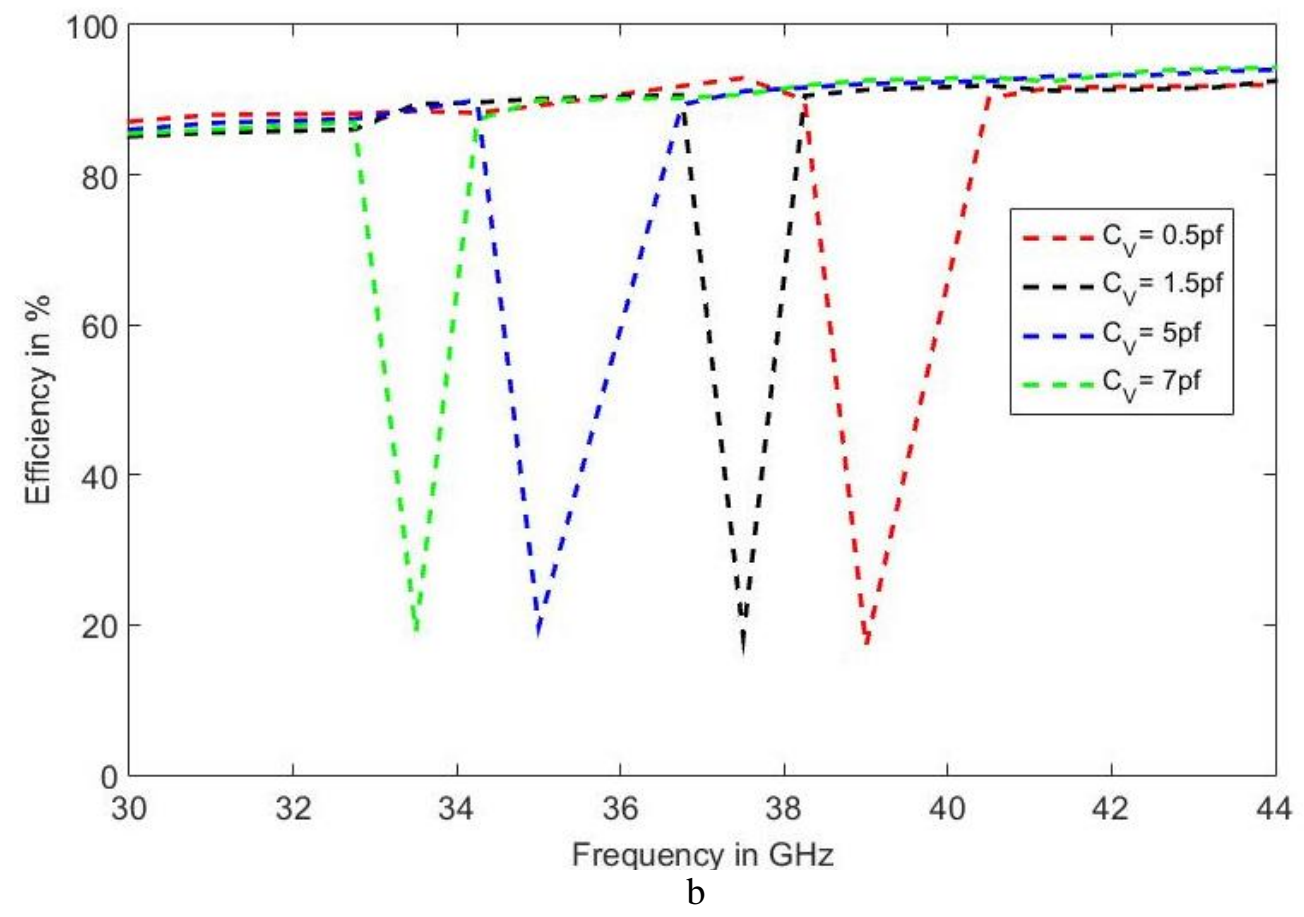

Figure 8 . The power gains (a) and effiecnies (b) of the proposed antennas with attached capacitor

Moreover, the resonant behaviour of the proposed antenna designs (DGP, DGP and L-slot, and the tuneable notch design) are given by Figure 9, where the simulated analysis of the current surfaces are given; four resonant frequencies were selected to cover the aggregated obtained 
bandwidth, namely $30 \mathrm{GHz}, 33 \mathrm{GHz}, 37 \mathrm{GHz}$ and $40 \mathrm{GHz}$. The current distributions of the antenna with only DGP demonstrate that most of the currents flow along the microstrip feeding line at the four targeted frequencies (See figure 9.a) in which the filtering feature (no rejected band) was not included within this version. However, in the case of the proposed antenna with both DGP and Lslot, the main currents within this version appear or are induced on the feeding line, except at the frequency of $40 \mathrm{GHz}$, where a strong current flows along the strip line and the L-slot, as the desired north was generated as shown in Figure 9. b ; this leads to the conclusion that the embedded Lslot acts as a resonator to be used as an effective and simple band-rejection technique. In the scenario of the tunable notch antenna (antenna with attached capacitor), while the antenna loaded with $1.5 \mathrm{pf}$ and $7 \mathrm{pf}$ as illustrated in Figure $9 \mathrm{c}$ and $\mathrm{d}$, the current distributions were mostly concentrated around the feeding strip and at the boundaries of the L-slot. These currents cancel each other out prevent the antenna from radiating at $37 \mathrm{GHz}$ and $33 \mathrm{GHz}$ where the rejected bands were produced, respectively. This means the antenna impedance will abruptly be changed at the desired rejected bands, which in turn introduces the notched band into the proposed monopole antenna structure.

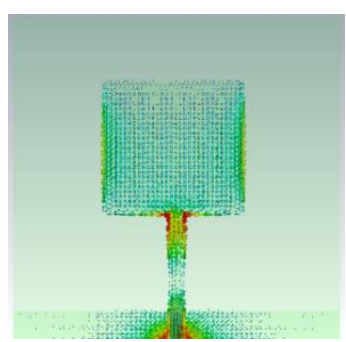

$30 \mathrm{GHz}$

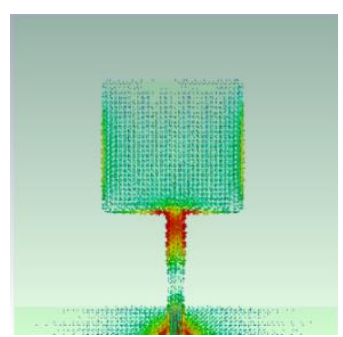

$33 \mathrm{GHz}$
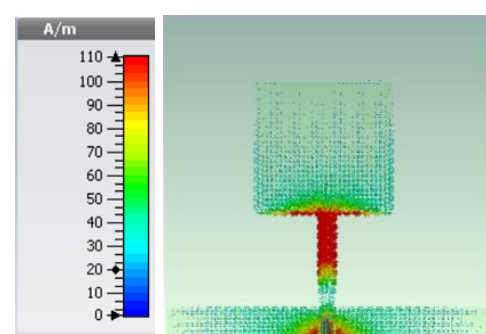

$37 \mathrm{GHz}$

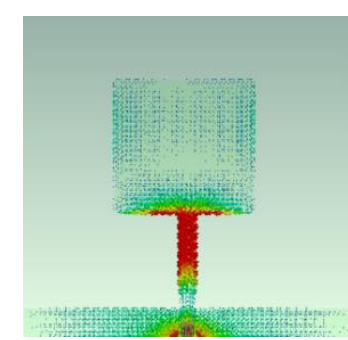

$40 \mathrm{GHz}$

(a)

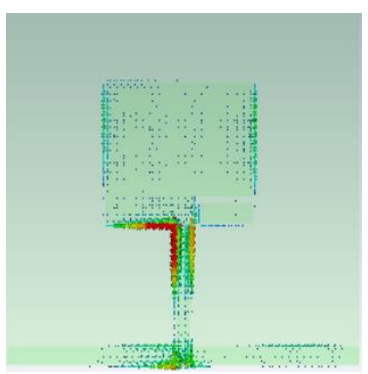

$30 \mathrm{GHz}$

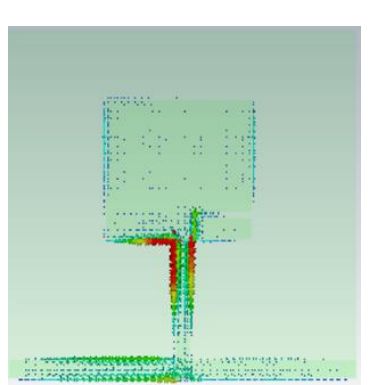

$33 \mathrm{GHz}$

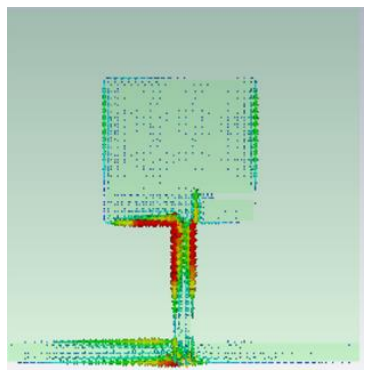

$37 \mathrm{GHz}$

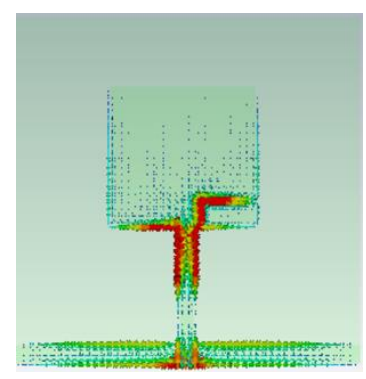

$40 \mathrm{GHz}$

(b)

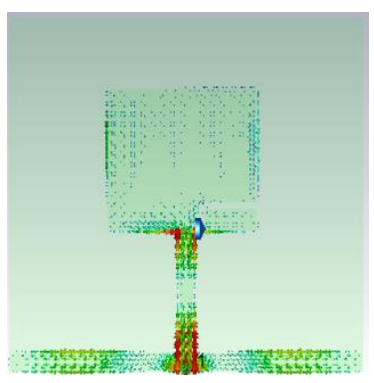

$30 \mathrm{GHz}$

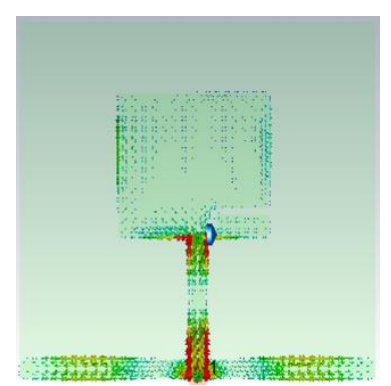

$33 \mathrm{GHz}$

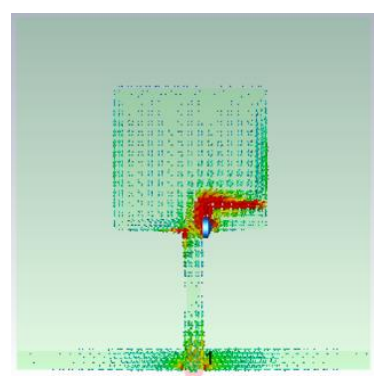

$37 \mathrm{GHz}$

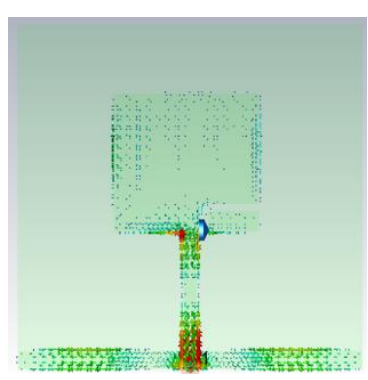

$40 \mathrm{GHz}$

(c) 


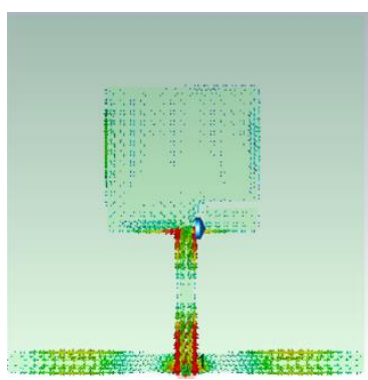

$30 \mathrm{GHz}$

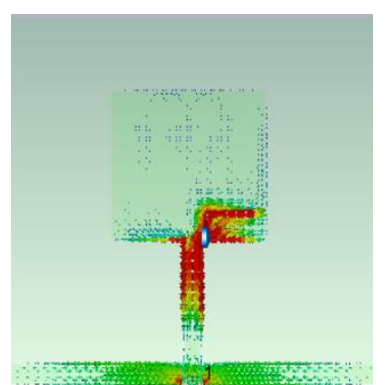

$33 \mathrm{GHz}$

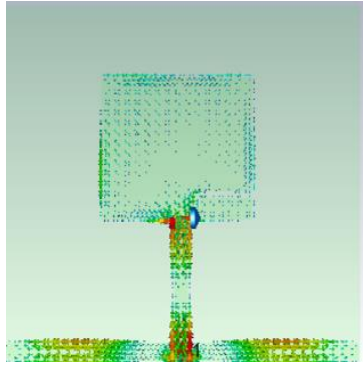

$37 \mathrm{GHz}$

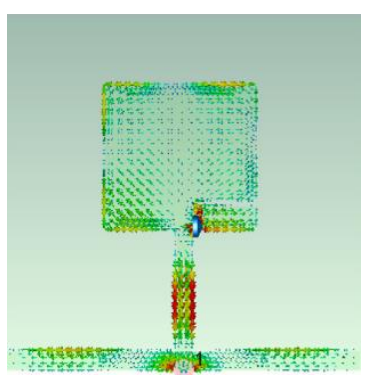

$40 \mathrm{GHz}$

(d)

Figure 9. The current surfaces for (a) the unslotted antenna, (b) slot antenna, (c) $1.5 \mathrm{pf}$ loaded antenna, (c) $7 \mathrm{pf}$ loaded antenna at $30 \mathrm{GHz}, 33 \mathrm{GHz}, 37 \mathrm{GHz}$ and $40 \mathrm{GHz}$.

The 3D radiation patterns of the antennas and their fundamental properties in terms of total efficiency and directivity are indicated in Figure 10. Four frequency bands at $30 \mathrm{GHz}, 32 \mathrm{GHz}$, $36 \mathrm{GHz}$ and $42 \mathrm{GHz}$ were selected to cover the entire wide frequency range of the proposed design. As can been seen from Figure 10, the proposed antenna achieve a desirable radiation performances over the four targeted bands of interest. It is clear that the antenna's behaviour is the same as an omnidirectional antenna in the frequency range of interest.

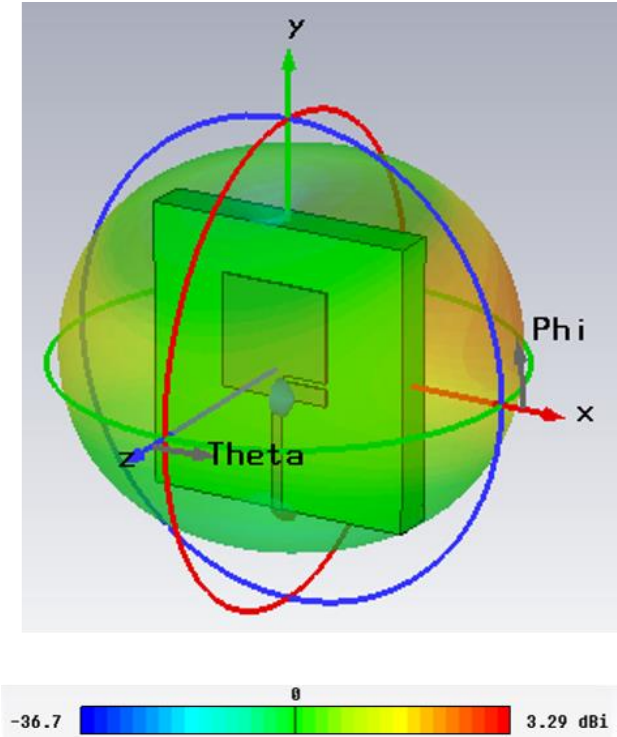

(a) at $30 \mathrm{GHz}$
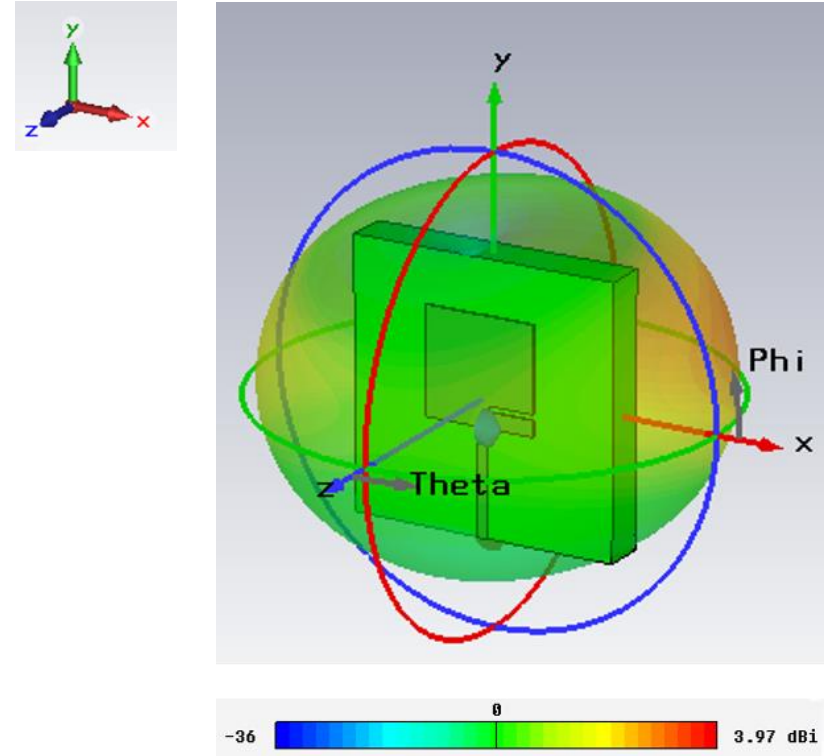

(b) at $32 \mathrm{GHz}$ 


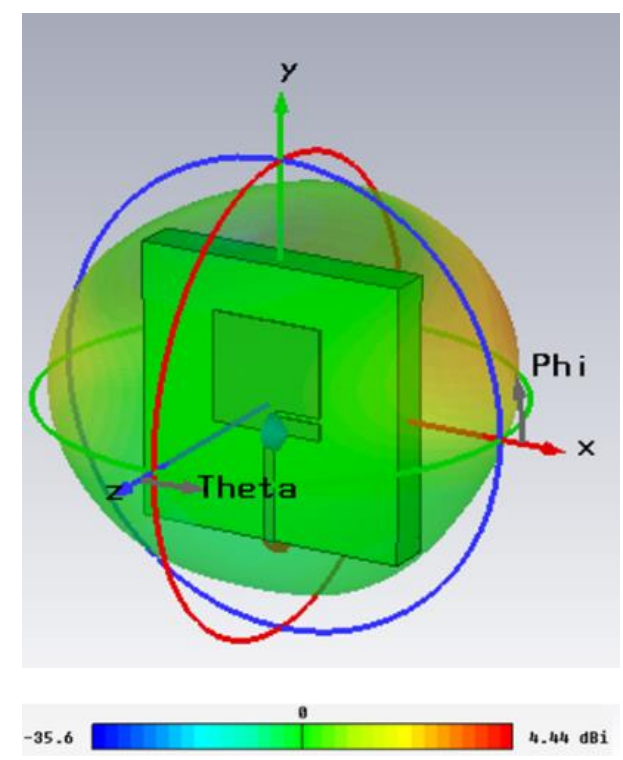

(c) at $36 \mathrm{GHz}$

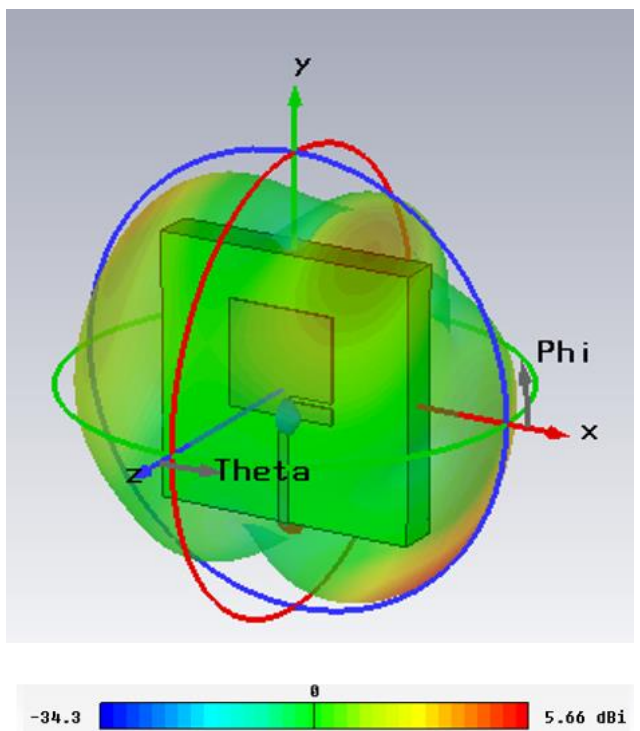

(d) at $42 \mathrm{GHz}$

Figure 10. The Radiation pattern of the proposed loaded antenna at $30 \mathrm{GHz}, 32 \mathrm{GHz}$, $36 \mathrm{GHz}$ and $42 \mathrm{GHz}$.

\section{Conclusion}

MMwave broadband monopole antennas, which are suitable for future 5G mobile networks applications have been presented. The proposed antennas occupy compact volume of $2.5 \times 2.5 \mathrm{~mm}^{2}$ that is printed over RF4 substrate with size of $5 \mathrm{~mm} \times 5 \mathrm{~mm} \times 0.8 \mathrm{~mm}^{3}$. The first antenna version without the DGP exhibits a narrow bandwidth of around $37.5 \mathrm{GHz}$. The second version exploits the defected ground plane approach has results in wide frequency range of operation from $30 \mathrm{GHz}$ to $45 \mathrm{GHz}$. In addition, to reduce the foreseen interferences between $5 \mathrm{G}$ systems and other applications, an L-shaped slot was inserted in a proper location over the radiator to generate a notched band at around $40 \mathrm{GHz}$. Finally, to tune the created filtering band, a lumped capacitor has been attached over the L-shaped slot, by varying its capacitance values from $0.5 \mathrm{pf}$ to $7 \mathrm{pf}$. This led to a downward shift in the notch from $40 \mathrm{GHz}$ up to $33 \mathrm{GHz}$, while keeping the same wide bandwidth $(30 \mathrm{GHz}$ to $45 \mathrm{GHz})$ constant. The proposed antennas demonstrate promising performances in terms of return loss, power gain, current surfaces and efficiency, that ultimately characterises them as attractive candidate solutions for future $5 \mathrm{G}$ wireless systems.

\section{Acknowledgment}

This work is carried out under the grant of the Fundacão para a Ciência e a Tecnologia (FCT Portugal), with the reference number: SFRH / BPD / 95110 / 2013. This work is supported by the European Union's Horizon 2020 Research and Innovation program under grant agreement H2020-MSCA-ITN-2016-SECRET-722424. 


\section{References}

1- L. Q. Orellana and K. Solbach, "Study of Monopole Radiators for Planar Circuit Integration," Proceedings of the 38th European Microwave Conference, EuMC 2008, pp. 1300-1303, 2008.

2-S. C. Pan and K.-L. Wong, ĀDual-Frequency Triangular Microstrip Antenna with A Shorting Pin,āIEEE Trans. Antennas Propagat., vol.45, no.12' pp.1889-1891, Dec.1997.

3- H. Nakono, H. Tagami, A. Yoshizawa, and J. Yamauchi, "Shortening Ratios of Modified Dipole Antennas,” IEEE Trans. Antennas Propagat., vol.32, no.4, pp. 385-386, Apr. 1984.

4- C. -W. Huang, A. Z. Elsherbeni, J. -J. Chen, and C. E. Smith, "FDTD Characterization of Meander Line Antennas for RF and Wireless Communications," Journal of Electromagnetic Waves and Applications, vol.13, no.12, p1649-1651, 1999.

5- K. R. Boyle and P. G. Steeneken, "A Five-Band Reconfigurable PIFA for Mobile Phones," IEEE Trans. Antennas Propagat., vol. 55, No. 11, pp. 3300-3309, Nov. 2007.

6- V. K. Palukuru, M. Komulainen, M. Berg, H. Jantunen, and E. Salonen, "Frequency-Tunable Planar Monopole Antenna for Mobile Terminals," 2nd European Conference on Antennas and Propagation, EuCAP 2007.

7- Hong Y, Tak J, Baek J, Myeong B, Choi J. Design of a multiband antenna for LTE/GSM/UMTS band operation. Int J Antennas Propag. 2014.

8- I. T. E Elfergani, A. S. H. J. Rodriguez, and R. A. Abd-Alhameed, "A compact dual-band balanced slot antenna for LTE applications," PIERS Proceedings, 524-527, Prague, Jul. 6-9, 2015.

9- Sethi WT, Vettikalladi H, Fathallah H, Himdi M. Hexa-band printed monopole antenna for wireless applications. Microw Opt Technol Lett. 2017;59:2816-2822.

10-Issa Elfergani, Abubakar Sadiq Hussaini, Jonathan Rodriguez, Chan H See, Read Abdalhameed "Wideband Tunable PIFA Antenna with Loaded Slot Structure for Mobile Handset and TE Applications ", Radioengineering, Vol. 23, No. 1, pp. 345 - 355, April, 2014.

11- I.T.E.Elfergani, Abubakar Sadiq Hussaini Jonathan Rodriguez, and R.A.Abd-Alhameed "Dual-Band Printed Folded Dipole Balanced Antenna for 700/2600MHz LTE Bands", The 10th European Conference on Antennas and Propagation (EuCAP2016), Davos, Switzerland, pp 1-5, on 10-15 April 2016.

12- Belrhiti L, Riouch F, Terhzaz J, Tribak A, Sanchez AM. A compact planar monopole antenna with a T-shaped coupling feed for LTE/GSM/UMTS operation in the mobile phone. In: El Oualkadi A, Choubani F, El Moussati A, eds. Proceedings of the Mediterranean Conference on Information \& Communication Technologies 2015. Cham: Springer; 2016. Lecture Notes in Electrical Engineering; vol 380.

13- First Report and order, "Revision of part 15 of the commission's Rule Regarding UltraWideband Transmission System FCC 02-48," Federal Communications Commission, 2002.

14-Issa Elfergani, Abubakar Sadiq Hussaini, Jonathan Rodriguez and R.A. Abd-Alhameed "Antenna Fundamentals for Legacy Mobile Applications and Beyond" Springer International Publishing, Cham, Switzerland, 2017. ISBN 978-3-319-63967-3. 
15- K. P. Ray, S. S. Thakur, A. A. Deshmkh "Compact Slotted Printed Monopole UWB Antenna" International Conference on Communication Technology, pp.16-18.2013.

16- Xun Gong, Ling Tong, Yu Tian, and Bo Gao "Design of a Microstrip-Fed Hexagonal Shape UWB Antenna with Triple Notched Bands" Progress In Electromagnetics Research C, Vol. 62, 77-87, 2016.

17- Muhammad Kabir Khan, Muhammad Irshad Khan, Iftikhar Ahmad, and Mohammad Saleem "Design of a Printed Monopole Antenna with Ridged Ground for Ultra Wideband Applications" 2016 Progress In Electromagnetic Research Symposium (PIERS), Shanghai, China, 8-11 August. pp. 4394- 4396.

18- Sk.Waseem Akram, K Shambavi, Zachariah C Alex " Design of Printed Strip Monopole Antenna for UWB Applications" IEEE Second INTERNATIONAL CONFERENCE ON ELECTRONICS AND COMMUNICATION SYSTEM (ICECS). 26-27 Feb. 2015 . Coimbatore, India pp823-826.

19- Josiel do Nascimento Cruz, Raimundo Carlos Silvério Freire, Alexandre Jean René Serres “ Parametric Study of Printed Monopole Antenna Bioinspired on the Inga Marginata Leaves for UWB Applications" Journal of Microwaves, Optoelectronics and Electromagnetic Applications, Vol. 16, No. pp.312-321. March 2017.

20- Pengcheng Li, Jianxin Liang, and Xiaodong Chen "Study of Printed Elliptical/Circular Slot Antennas for Ultra wideband Applications" IEEE TRANSACTIONS ON ANTENNAS AND PROPAGATION, VOL. 54, No. 6, pp. 1670 - 1675. JUNE 2006.

21- Muhammad Abid, Jalil Kazim and Owais "Ultra-Wideband Circular Printed Monopole Antenna for Cognitive Radio Applications" INTERNATIONAL JOURNAL OF MICROWAVE AND OPTICAL TECHNOLOGY, Vol.10, No.3, pp. 184-189.MAY 2015.

22-I.T.E. Elfergani , A. S Hussaini, C See, R.A. Abd-Alhameed Abd-Alhameed, N.J McEwan , S. Zhu , J. Rodriguez, R. W. Clarke, Printed Monopole Antenna with Tunable Band-Notched Characteristic for Use in Mobile and Ultra-Wide Band Applications, International Journal of RF and Microwave Computer-Aided Engineering/Vol. 25, No. 5, PP. 403-412. June 2015.

23-I.T.E. Elfergani, R.A Abd-Alhameed, C.H. See, S.M.R. Jones and P.S. Excell "A Compact Design of Tunable Band-Notched Ultra-Wide Band Antenna" Microwave and Optical Technology Letters, Vol. 54, No. 7, pp. 1642-1644. July 2012.

24-M. Naser-Moghadasi, R. A Sadeghzadeh, T. Sedghi, T. Aribi, and B. S. Virdee" UWB CPWFed Fractal Patch Antenna With Band-Notched Function Employing Folded TShaped Element" IEEE ANTENNAS AND WIRELESS PROPAGATION LETTERS, VOL. 12,2013.

25-Y. Sung "Triple Band-Notched UWB Planar Monopole Antenna Using a Modified H-Shaped Resonator "IEEE Transaction on Antenna and Propagation, VOL. 61, NO. 2, February 2013.

26- Zhang C-W, Yin Y-Z, Liu P-A, et al. Compact dual band-notched UWB antenna with hexagonal slotted ground plane. J. Electromagnet. Waves Appl. 2013;27:215-223.

27- Karmakar A, Ghatak R, Banerjee U, et al. An UWB antenna using modified Hilbert curve slot for dual band notch characteristics. J. Electromagnet. Waves Appl. 2013;27:1620-1631.

28- Abdollahvand M, Dadashzadeh G, Mostafa D. Compact dual band-notched printed monopole antenna for UWB application. IEEE Antennas Wirel. Propag. Lett. 2010;9:1148-1151. 
29 Emadian SR, Ahmadi-Shokouh J. Very small dual band-notched rectangular slot antenna with enhanced impedance bandwidth. IEEE Trans. Antennas Propag. 2015;63:4529-4534.

30- Lin C, Jin P, Ziolkowski R. Single, dual and tri-band-notched ultrawideband (UWB) antennas using capacitively loaded loop (CLL) resonators. IEEE Trans. Antennas Propag. 2012;60:102109.

31- Sung Y. Triple band-notch UWB planar monopole antenna using a modified H-shaped resonator. IEEE Trans. Antennas Propag. 2013;61:953-957.

32- Gorai A, Karmakar A, Pal M, et al. Multiple fractal-shaped slots-based UWB antenna with tripleband notch functionality. J. Electromagnet. Waves Appl. 2013;27:2407-2415.

33- Reddy GS, Kamma A, Mishra SK, et al. Compact bluetooth/UWB dual-band planar antenna with quadruple band-notch characteristics. IEEE Antennas Wirel. Propag. Lett. 2014;13:872-875

34- M. Elkashlan, T. Q. Duong, H. -H. Chen, "Millimeter-wave communications for 5G: fundamentals: PartI [Guest Editorial]," IEEE Communications Magazine, vol. 52, no. 9, pp. 52 54, 2014.

35- Straightpath Communication Inc. "A straight Path Towards 5G (white paper)" September 16, 2015.

36- R. M. Shubair, A. M. AIShamsi, K. Khalaf, and A. Kiourti, "Novel miniature wearable microstrip antennas for ISM-band biomedical telemetry," in Antennas Propagation Conference (LAPC), 2015 Loughborough, pp. 1-4.

37-Wong, H., K. B. Ng, C. H. Chan, and K. M. Luk, "Printed antennas for millimeter wave application," International Workshop on Antenna Tech., 411-414, 2013.

38-Chin, K. S., H. T. Chang, J. A. Liu, et al., "28-GHz patch antenna arrays with PCB and LTCC substrates," Cross Strait Quad-Regional Radio Science and Wireless Technology Conference, Vol. 1, 355-358, 2011.

39-Tong, K. F., K. Li, and T. Matsui, "Performance of millimeter-wave coplanar patch antennas on low-k materials," PIERS Online, Vol. 1, No. 1, 46-47, 2005.

40-Wang, D., H. Wong, K. B. Ng, and C. H. Chan, "Wideband shorted higher-order mode millimeter- wave patch antenna," IEEE Antennas and Propagation Society International Symposium, 5-6,2012.

41-Balanis, C. A., Antenna Theory: Analysis and Design, Wiley-Interscience, New Jersey, 2005. 8. Jamaluddin, M. H., R. Gillard, R. Sauleau, et al., "A dielectric resonator antenna (DRA) reecarray," Proc. European Microwave Conference., 25-28, 2009.

42-Hidayat Ullah, Farooq A. Tahir, Muhammad U. Khan “ A Honeycomb-Shaped Planar Monopole Antenna for Broadband Millimeter-wave Applications" 2017 11th European Conference on Antennas and Propagation (EUCAP). Pp3094-3097. 
43-M. Khalily, R. Tafazolli, T. Rahman, and M. Kamarudin, "Design of Phased Arrays of SeriesFed Patch Antennas With Reduced Number of the Controllers for 28-GHz mm-Wave Applications," IEEE Antennas and Wireless Propagation Letters, vol. 15, pp. 1305-1308, 2016.

44-J. B. Diaaaldin, S. Liao, and Q. Xue, "High Gain and Low Cost Differentially Fed Circularly Polarized Planar Aperture Antenna for Broadband Millimeter-Wave Applications," IEEE Transactions on Antennas and Propagation, vol. 64, no. 1, pp. 33-42, 2016.

45-P. N. Choubey, W. Hong, Z.-C. Hao, P. Chen, T.-V. Duong, and J. Mei, "A Wideband DualMode SIW Cavity-Backed Triangular-ComplimentarySplit-Ring-Slot (TCSRS) Antenna," IEEE Transactions on Antennas and Propagation, vol. 64, no. 6, pp. 2541-2545, 2016.

46-S.-J. Park, D.-H. Shin, and S.-O. Park, "Low Side-Lobe Substrate Integrated-Waveguide Antenna Array Using Broadband Unequal Feeding Network for Millimeter-Wave Handset Device," IEEE Transactions on Antennas and Propagation, vol. 64, no. 3, pp. 923-932, 2016.

47-A. Dadgarpour, B. Zarghooni, B. Virdee, and T. Denidni, "Single EndFire Antenna for DualBeam and Broad Beamwidth Operation at $60 \mathrm{GHz}$ by artificially modifying the Permittivity of the Antenna substrate."

48- CST-Computer Simulation Technology AG, 2014.

49- Gary Breed," An Introduction to Defected Ground Structures in Microstrip Circuits," High Frequency Electronics Copyright ( 2008 Summit Technical Media, LLC. 